\title{
Prefabricated Timber Concrete Composite Floors
}

\author{
Thomas TANNERT ${ }^{1 *}$ \\ ${ }^{1}$ Associate Professor, Integrated Wood Engineering, University of Northern British Columbia \\ "Corresponding author's e-mail: thomas.tannert@unbc.ca
}

\begin{abstract}
Timber-concrete-composite (TCC) floors are an example of hybrid systems that integrate different materials to achieve superior performance than the individual materials can provide. The structural and non-structural benefits of TCC floors over generic timber floors include increased capacity and stiffness, shallower depth, improved sound protection, and superior fire performance. Rapid erection due to the use of the timber as formwork, more economical gravity systems and foundations due to lighter weight, lower embodied energy, and reduced carbon footprint are advantages when comparing TCC systems to concrete slabs. This paper gives an overview of recent developments including research carried out on three novel solutions: 1) the "Swiss-Wood-Concrete-Floor"; 2) adhesively bonded TCC; and 3) "FT connectors" that are embedded in precast concrete. All three solutions are well suited for modular and off-site construction and show the potential of using wood products beyond current limitations.
\end{abstract}

\section{KEYWORDS}

Timber-concrete-composite; Hybrid construction; Multi-functionality; Adhesive bonding

\section{INTRODUCTION}

Hybrid systems that integrate different materials can significantly increase the applications of timber in structures, allowing current building code limitations regarding maximum number of stories to be revised. The hybrid design framework is particularly interesting for its ease of assembly. Since hybrid systems involve two or more materials, corresponding design procedures usually overlap different engineering codes and standards, rendering design and detailing challenging. The development of design guidelines for hybrid structures, however, is of fundamental importance to the industrial acceptance of novel hybrid solutions.

Timber-concrete-composite (TCC) systems, a successful category of hybrid systems, were initially developed to refurbish historical buildings in Europe (Yeoh et al. 2011). An early example of a TCC system is the 1939 patent by Schaub in which hooks acted as shear connectors between timber beams and a concrete layer. TCC systems gained traction in the subsequent decades, and research on TCC systems intensified and the resulting theories were applied in practice by the mid-1980s. 
Structural and non-structural benefits of TCC floors over generic timber floors, such as increased floor capacity and stiffness, shallower floor depth, reduction in floor weight, and improved acoustic and fire performance, have led to increased attention and widened application of TCC systems. Additional advantages when compared to a concrete slab are found in the rapid erection of the system due to the use of the timber element as formwork, more economical gravity systems due to lighter weight, lower embodied energy, and reduced carbon dioxide emissions (Clouston and Schreyer 2008).

Due to increasing demand for TCC systems, easy to use methods had to be developed to satisfy practitioners. The $\gamma$ method developed by Moehler (1956) - currently used in Eurocode 5 (CEN 2004) - is based on the effective bending stiffness and accounts for the capacity of connectors to achieve composite action (Yeoh et al. 2011). In order to ensure that a TCC system satisfies fire code requirements, the clauses for both materials must be considered to ensure corresponding material code compliance. In recent years, significant research has been undertaken on the fireresistance of TCC structures (e.g. Frangi et al. 2010) and confirmed that TCC floors perform better in fire than timber floors. Research on other aspects of TCC systems, such as the vibration and long-term behaviour (e.g. Fragiacomo and Schänzlin 2013) is ongoing.

While heavy timber mid-rise construction was an accepted practice in the early $20^{\text {th }}$ century in Canada, nowadays, as a result of conservative design codes developed throughout the $20^{\text {th }}$ century, the use of timber as a structural material is largely limited to residential light-frame construction. TCC floors offer the potential for an increased use of timber in non-residential construction (Dias et al. 2016). One prominent example that showcases the innovative use of wood is the Earth Sciences Building in Vancouver. It is best known for its free-standing timber staircase but more relevant in the context of this paper is that the building is one of the first applications of a TCC floor in Canada. As an alternative building solution, a series of full scale bending tests were required, see Figure 1 (right). Since the system performance according to the design predictions, it was implemented in the ESB.
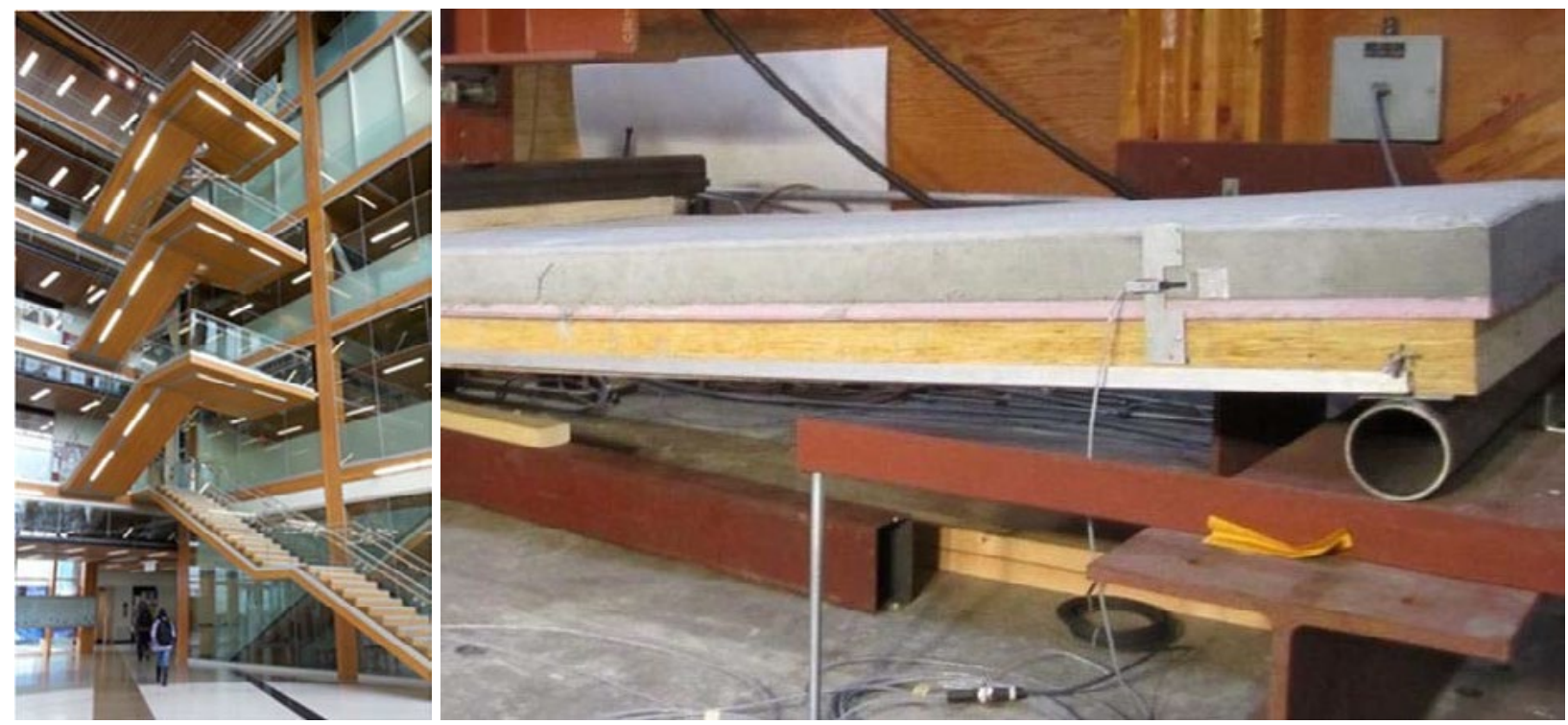

Figure 1: Earth Sciences Building staircase (left) and TCC floor tests (right) (Dias et al. 2015) 


\section{SWISS-WOOD-CONCRETE DECK}

Commonly, TCC systems are optimized for structural functionality, with the concrete loaded in compression and the timber loaded in tension. When multi-functionality requirements such as building physics or fire protection are added as optimization targets, other solutions of the structural form of hybrid systems - solutions that challenge common engineering conceptions can emerge as an optimal choice (Hehl et al. 2014). One such radically different concept for a TCC system was developed in the framework of the project "Swiss-Wood-Concrete Deck" at the Bern University of Applied Sciences, Switzerland. The goal was to design a completely prefabricated floor system that, besides structural functions, integrates floor heating and cooling, and a sprinkler system. To make the TCC system particularly suitable for prefabrication and fast erection on site, i.e. to overcome the commonly encountered problem of connecting a TCC floor to a timber wall, an unconventional set-up with timber beams on top was developed.

The system, shown in Figure 2, consists of $6 \mathrm{~m} \times 3 \mathrm{~m}$ elements, which are to be delivered to site ready for installation. This novel set-up provides most of the advantages of traditional TCC floors: it is lighter in weight than a concrete floor and it has better acoustical properties compared to a light-weight timber floor. Additionally, the system significantly improves the integration of mechanical installations using the concrete layer as a thermos-active element; the connection to timber structural systems; and the fire resistance of the system. The system is completed with a glued-on laminated veneer lumber panel on top, which serves as the base for the floor build-up. Self-compacting high-strength concrete that enables rapid and economic production is used. The system is additionally equipped with an extensive embedded water piping system, which is actively regulated by thermocouple wires to control the building temperature. In a statically determinate single-span application, and for positively defined bending moments, the timber is in compression. The selected Glulam timber exhibits approximately 20\% higher strength in compression than in tension; additionally, timber favourably behaves in a ductile manner in compression, as opposed to its brittle behaviour in tension. The concrete layer is in tension; although concrete is usually not intended to carry tension forces; in the novel system, reinforcement is required to carry the tension force.

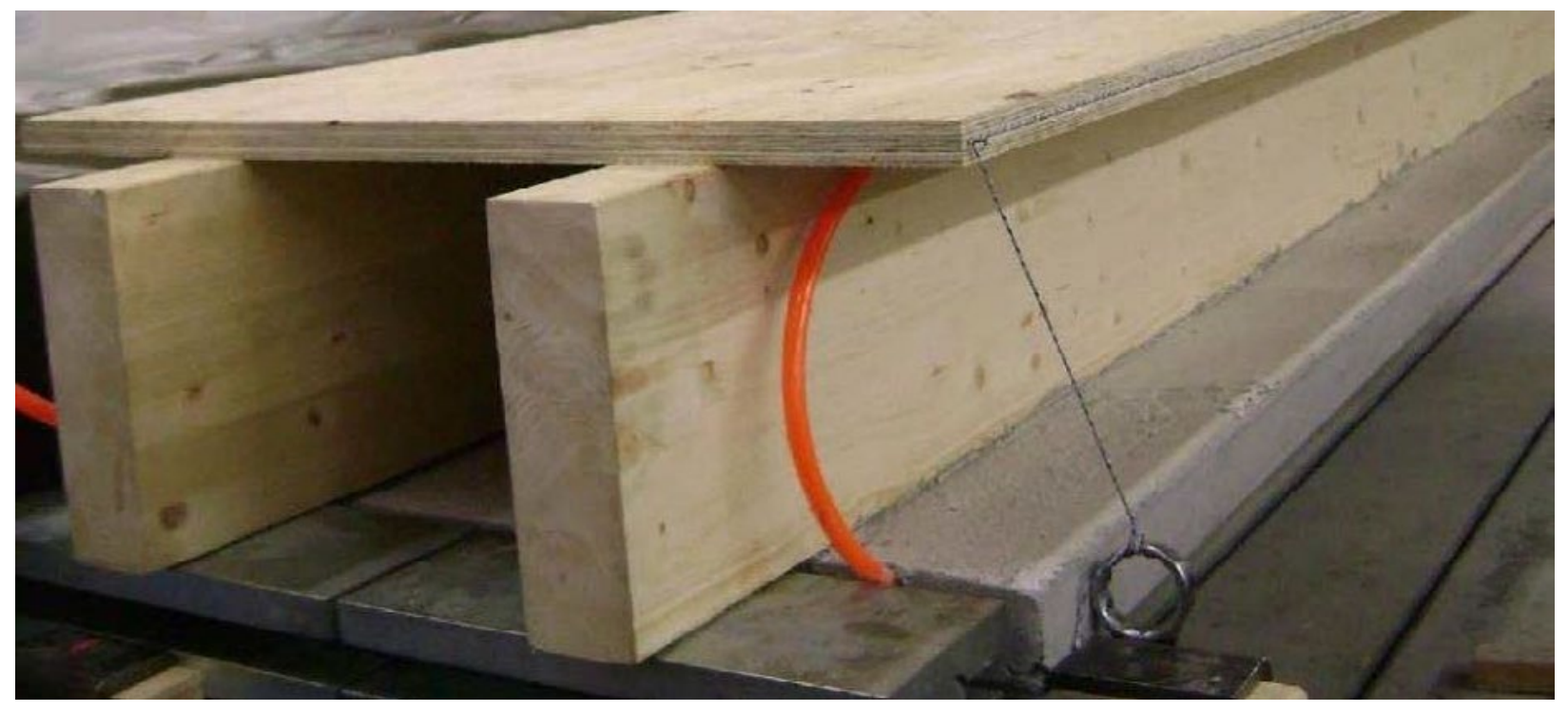

Figure 2. Swiss Wood Concrete Deck (Hehl et al. 2014) 
The connection between timber and concrete is achieved by means of grooves milled into the timber beams leading to mechanical interlocking, see Figure 3 (top). The grooves fulfill the dual purpose of providing the shear connection between the two materials resulting and the vertical connection, i.e. dead load of the concrete layer, between both components of the TCC. The groove connector was chosen for its ease of assembly and its low cost. This type of connector has been proven to be efficient and stiff in pre-fabricated TCC applications. The results from full-scale bending tests, and shear and tension tests on a sub-section of the system show that the grooves cut into the timber beams transmit the shear forces, and sufficiently connect the concrete deck vertically to the timber (Hehl et al. 2014). Subsequently, the structural behaviour was numerically modeled, see Figure 3 (bottom), and the agreement between experimental and numerical results allow for the validated model to be used for geometric optimizations and predicting the performance of optimized systems.

The results from fire tests on a sub-section of the system were reported by Meena et al. (2014). The concrete side of one test specimen was subjected to a fire according the ISO-834 standard temperature-time curve and proofed to achieve a 60-minute fire rating. Subsequently, the temperature behaviour was numerically modeled by performing a transient thermal analysis with temperature dependent material properties. The temperature profiles for the TCC system was accurately modeled allowing for the validated model to be used for future optimizations and predicting the fire resistance ratings of optimized systems.
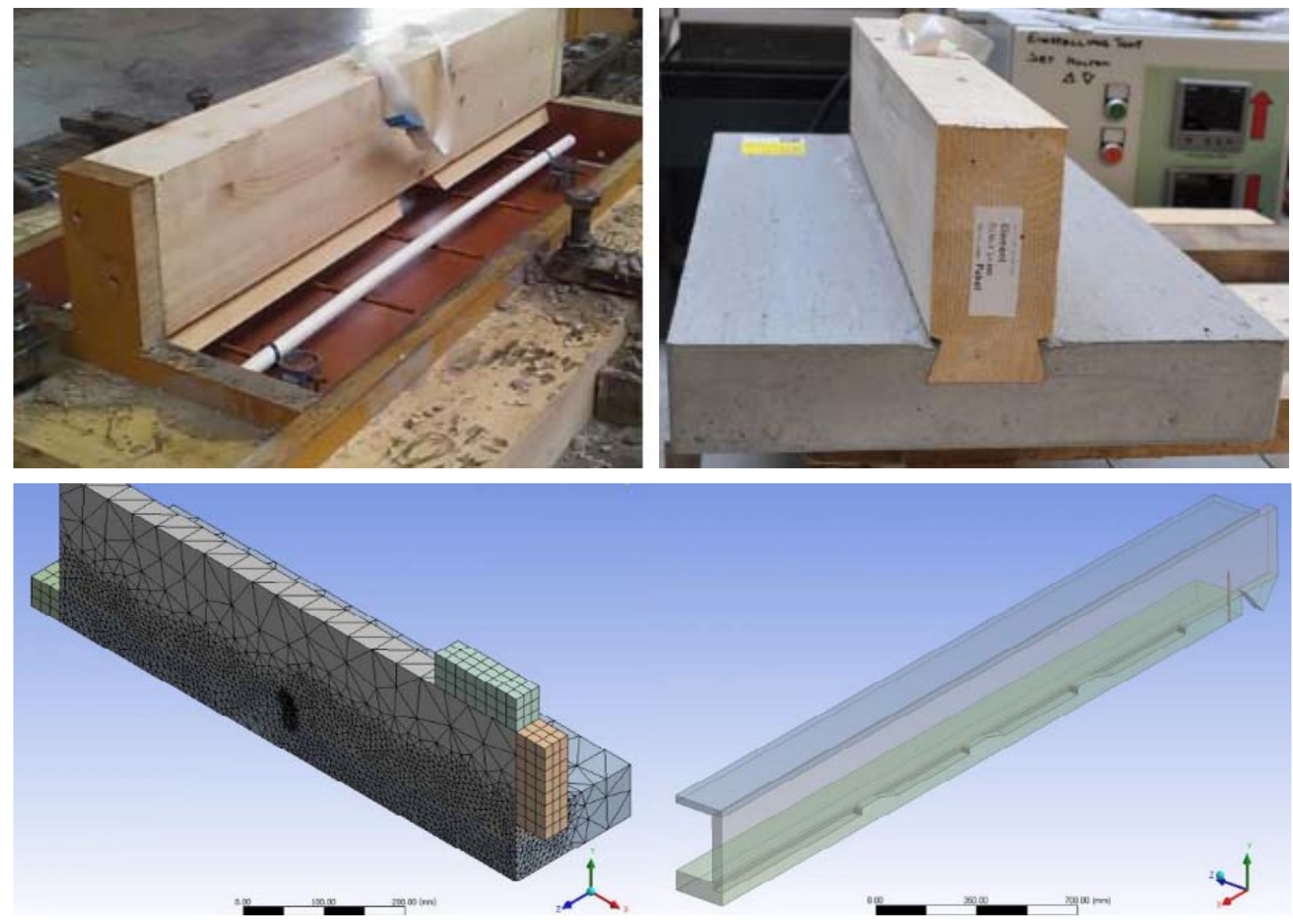

Figure 3. Swiss Wood Concrete Deck: Shear tests (top) and model (bottom) (Hehl et al. 2014) 


\section{ADHESIVELY BONDED TIMBER-CONCRETE-COMPOSITES}

Traditionally, TCC shear connections have been achieved through mechanical means. Only since the turn of the millennium has there been an increase in interest and research into adhesive bonded systems (Brunner et al. 2007; Negrão et al. 2010; Schäfers and Seim 2010). Advantages of glued TCCs include high strength and stiffness, reduced workmanship and costs, and potentially increased durability. There are, however, also significant challenges to glued interfaces including the mostly brittle failure of stiff adhesives, the sensitivity of the bond-line to hygrothermal changes (different responses of timber, concrete, and adhesive), and limited information on the fire- and long-term behavior.

Brunner et al. (2007) investigated a wet-wet manufacturing process (applying fresh concrete onto an uncured two-component epoxy layer on top of timber) and concluded that standard concrete should be poured from low heights to avoid excessive adhesive displacement. Brunner et al. (2007) then tested small-scale specimens in shear, and full-scale specimens in short-term bending. The results confirmed that the adhesive formed a very stiff connection and that the beam's bending stiffness can be calculated assuming a fully rigid connection. Despite those findings, more research on the wet-wet process was deemed necessary, and a pilot structure was recommended to be built and monitored before an industrial application could be implemented.

In subsequent work, Tannert et al. (2014) reported on long-term loading for 4.5 years and subsequent destructive testing of two adhesively bonded TCC beams. At the interface of each beam, plastic half-pipes were placed to reduce the total weight and to create the possibility of running conduits through the finished floor, see Figure 4. During the long-term loading, the indoor environmental conditions and the deflections were monitored. After having been loaded for 4.5 years, the beams were tested to failure, resulting in findings that long-term loading caused no degradation of the adhesive bond. For design purposes, a simplified approach proved sufficient to approximate the observed deflections caused by creep and shrinkage.

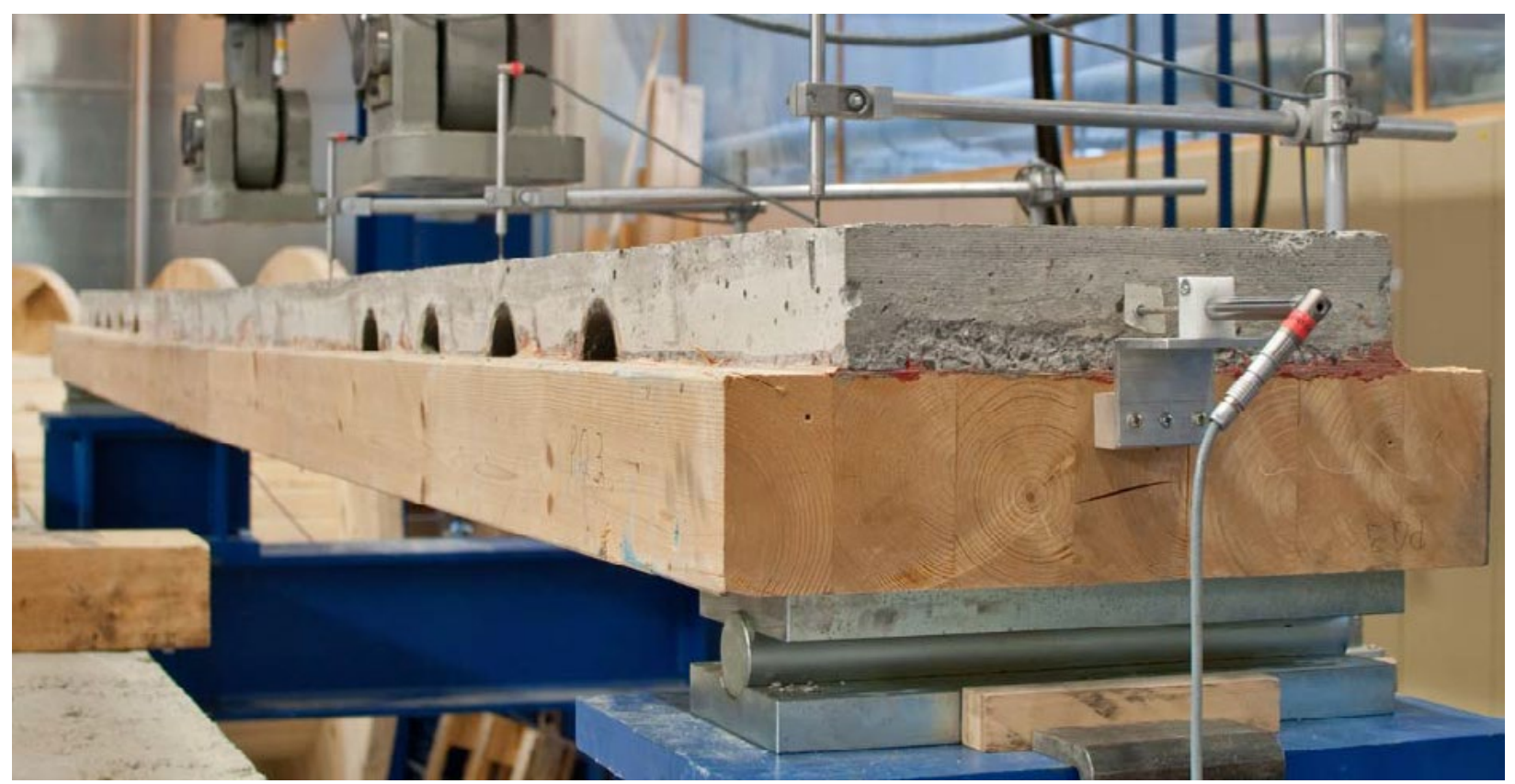

Figure 4. Adhesively Bonded Timber-Concrete-Composites 


\section{TIMBER-CONCRETE-COMPOSITES USING FT CONNECTOR}

A number of screw-type connectors have been implemented in TCC, and in their most efficient form, are installed at an angle to the grain to engage them axially rather than as a dowel. Aligning screws at an angle provides a significant increase in stiffness over fasteners installed perpendicular to the shear plane. Another system that is of particular interest for modular and off-site construction is the "Timtec plus VG screw" or so-called "FT connector" system.

The "FT connector", shown in Figure 5, is a proprietary product with a European technical approval (ETA-12/0196). It is used to facilitate the installation of precast concrete panels to timber elements on-site to improve overall quality, reduce construction time, and prevent contact of wet concrete to the timber elements. The connector provides a hollow sleeve, inclined at $30^{\circ}$ from the horizontal plane with a large steel bearing washer through which a $10 \mathrm{~mm}$ diameter fully threaded self-tapping screw is installed to provide the necessary anchorage of the concrete to the timber. This assembly provides up to $87 \%$ utilization of the screw's tension strength in shear at the wood-concrete interface. The slab is required to be $70 \mathrm{~mm}$ thick to allow proper access to the concealed component.

Tests utilizing the FT connector system were performed at the University of British Columbia (Gerber and Tannert 2015) using 240mm long fully threaded screws and different engineered wood products. Despite the high load carrying capacity, the results captured several drawbacks to the system: the connectors proved to be less stiff than utilizing the same screw configurations, and more importantly, they exhibited higher levels of residual displacement following initial loading which translates into potentially large unrecoverable deformations in the final structure. The larger residual deformations are likely a result of oversizing of the hole through which the screw is installed in the FT connector. The gap between the edge of the sleeve and the screw then needs to be closed before the stiffer axial load path can be activated.

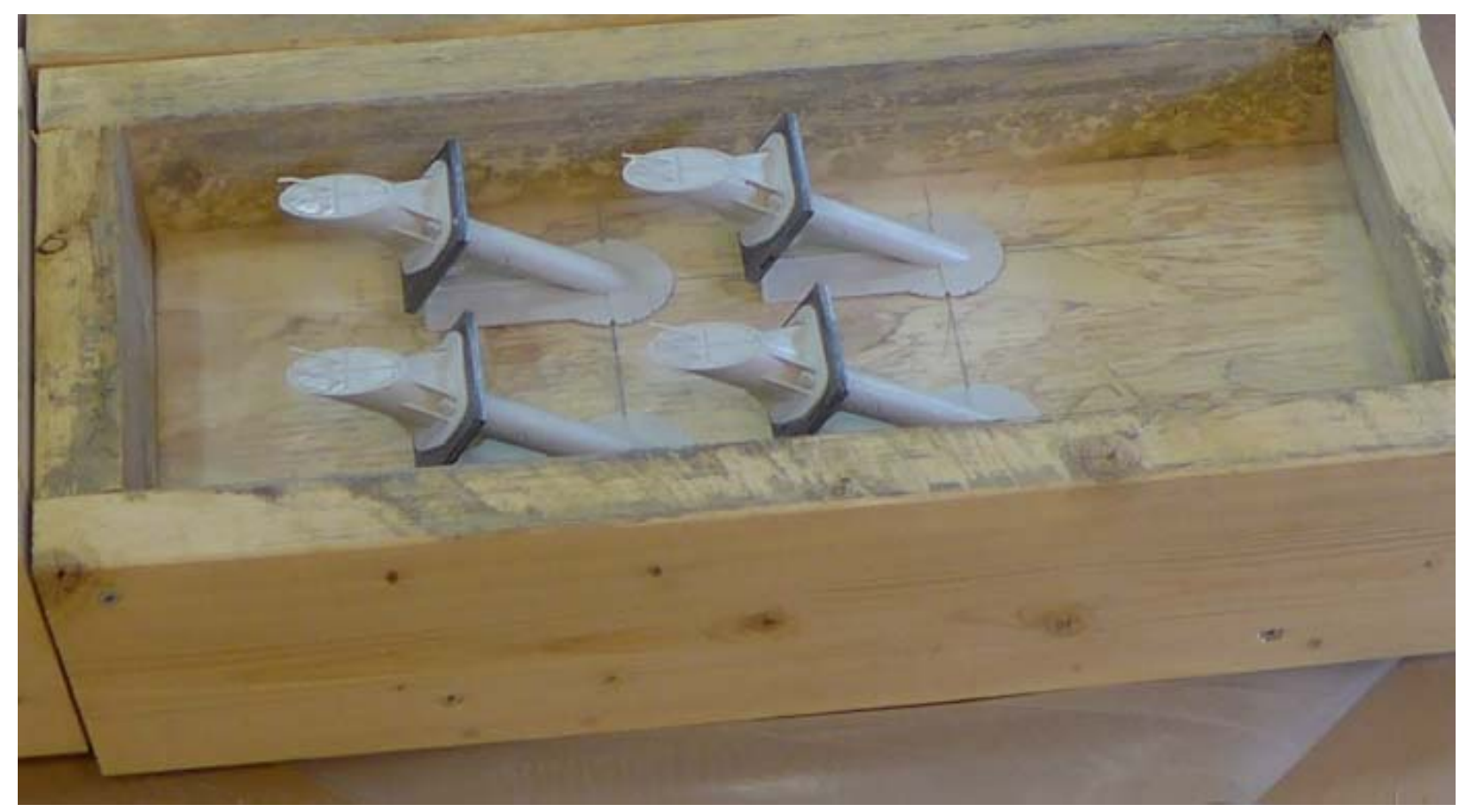

Figure 5. Timber-Concrete-Composites using FT connector 


\section{CONCLUSION}

This paper gives an overview of recent developments on three novel solutions for timberconcrete-composite floors that show the potential of using wood products in modular and off-site construction. For the "Swiss-Wood-Concrete-Floor", an unconventional set-up with timber beams on top was developed that integrates floor heating and cooling and a sprinkler system and is suitable for prefabrication and fast erection on site. Adhesively bonded TCC form very stiff connections but more research is necessary before industrial application. The "FT connectors" is used to facilitate the installation of precast concrete panels, prevents contact of wet concrete to timber and reduces construction time. An important step towards the increased use of TCC systems in Canada is obtaining the experimental proof that they can be designed safely and efficiently. Ongoing research at UBC and UNBC investigates the performance of different connector types in different engineered wood products including at hand of specimens subjected to long-term loading to analyse the creep behaviour.

\section{ACKNOWLEDGEMENTS}

This research on the Swiss-Wood-Concrete Deck was funded by the Swiss Commission for Technology and Innovation and carried out in collaboration with Renggli AG, Pirmin Jung Ingenieure für Holzbau AG, Makiol+Wiederkehr Holzbau-Ingenieure, Jomos Gruppe, and Rekag AG. This work on the Adhesively bonded TCC was supported by the Swiss Ministry of Education and the companies SIKA AG, Küng AG, and Schilliger AG. The experimental testing on the FT connectors was funded by NSERC and Forest Innovations Investment and supported by MyTiCon Timber Connectors. The help of the technicians at the Tech Park of the Bern University of Applied Sciences in Biel as well as the technicians at the University of British Columbia Vancouver and FPInnovations is greatly appreciated.

\section{REFERENCES}

Brunner M, Romer M, Schnüriger M (2007) Timber-concrete-composite with an adhesive connector (wet on wet process). Mater and Struct 40:119-126.

CEN (2004) EN 1995-2: 2004. Eurocode 5: Design of Timber Structures - Part 2: Bridges. Annex B. European Committee for Standardization, Brussels, Belgium.

Clouston P, Schreyer A. (2008) Design and use of wood-concrete composites. ASCE - practice periodical on Struct design and constr 13:167-174.

Dias A, Skinner J, Crews K, Tannert T (2016) Timber-concrete-composites increasing the use of timber in construction, European Journal of Wood and Wood Products. 74(3): 443-451 DOI 10.1007/s00107-015-0975-0.

Fragiacomo M, Schänzlin J (2013) Proposal to account for concrete shrinkage and environmental strains in design of timber-concrete composite beams. J Struct Eng 139:162-167.

Frangi A, Knobloch M, Fontana M. (2010) Fire design of timber-concrete composite slabs with screwed connections. J Struct Eng 136:219-228.

Gerber A, Tannert T (2015) Timber-concrete composites using flat-plate engineered wood products. ASCE Structures Congress, April 23-25, Portland, USA. 
Hehl S, Tannert T, Meena R, Vallee T (2014) Experimental and numerical investigations on groove connections for novel timber-concrete-composite system. Journal of Performance of Constructed Facilities, 28: A4014010; DOI: 10.1061/(ASCE)CF.1943-5509.0000549.

Meena R, Schollmayer M, Tannert T (2014) Experimental and numerical investigations on the fire-resistance of a novel timber-concrete-composite deck. Journal of Performance of Constructed Facilities, 28: A4014009; DOI: 10.1061/(ASCE)CF.1943-5509.0000539.

Möhler K (1956) Über das Tragverhalten von Biegeträgern und Druckstäben mit zusammengesetzten Querschnitten und nachgiebigen Verbindungsmitteln. Habilitation, Technische Universität Karlsruhe, Germany.

Negrão J, Leitão de Oliveira C, Maia de Oliveira F, Cachim P (2010a) Glued composite timberconcrete beams. I: Interlayer connection specimen Tests. J Struct Eng 136:1236-1245.

Schäfers M, Seim W (2010). Development of Adhesive Bonded Timber-UHPC Composites Experimental and Theoretical Investigations, Proceedings World Conference of Timber Engineering 2010, Riva del Garda, Italy.

Tannert T, Brunner M, Vallee T, Endacott B (2014) Long-term performance of adhesively bonded timber-concrete-composites. World Conference on Timber Engineering (WCTE 2014), August 10-14, Quebec City, Canada

Yeoh D, Fragiacomo M, De Franceschi M, Heng Boon K. (2011) State of the art on timberconcrete composite structures: Literature review. J Struct Eng 137:1085-1095. 